\title{
PRODUCTION OF TOCOLS NANOEMULSION BY ULTRASONICATION
}

\author{
PIK SEAH GOH*; NG MEI HAN**; CHOO, Y M**; NASRULHAQ BOYCE AMRU* \\ and CHENG HOCK CHUAH ${ }^{\ddagger}$
}

\begin{abstract}
Nanoemulsion has proven to be one of the efficient approaches to improve tocols (tocopherols and tocotrienols) solubility in aqueous solution. High energy emulsification method such as ultrasonication and microfluidisation has been widely applied. The objective of this study was to prepare palm-based tocols nanoemulsion using ultrasonication to produce small average droplet size $(<100 \mathrm{~nm})$ and narrow droplet size distribution with low polydispersity index (PDI) value. The optimal ultrasonication duration and amplitude of $80 \mathrm{~min}$ and $100 \%$ produced nanoemulsion of an average droplet size of $104.1 \pm 2.9 \mathrm{~nm}$ with PDI value of $0.215 \pm 0.008$. The mixing of Tween 80-Brij 35 (50:50 w/w) with concentration of $1.5 \%$ w/v produced an average droplet size of $54.8 \pm 1.2 \mathrm{~nm}$ and PDI of $0.266 \pm 0.006$. Although the increase of emulsifier concentrations to $3 \% \mathrm{w} / \mathrm{v}$ from $0.75 \% \mathrm{w} / \mathrm{v}$ produced an average droplet size of $45.4 \pm 1.0$ nm, PDI obtained was high $0.404 \pm 0.002$ indicating that the droplet size distribution was becoming less monodisperse. The produced nanoemulsion will be extruded into gelling solution to form calcium alginate beads. Total tocols encapsulate within the bead and release of tocols from the bead will be evaluated and reported in future study.
\end{abstract}

Keywords: nanoemulsion, ultrasonication, droplet size distribution, palm oil, tocopherol-tocotrienol, non-ionic emulsifiers, polysaccharides.

Date received: 28 March 2014; Sent for revision: 14 September 2014; Received in final form: 1 October 2015; Accepted: 20 November 2015.

\section{INTRODUCTION}

Vitamin $\mathrm{E}$ is one of the essential dietary supplements taken in order to prevent and to slow down the development of degenerative diseases (Gee, 2011). Vitamin E consists of three homologous series: tocopherols, tocotrienols and tocomonoenols $(\mathrm{Ng}$

\footnotetext{
* Institute of Biological Sciences, Faculty of Science, Universiti Malaya, 50603 Kuala Lumpur, Malaysia.

** Malaysian Palm Oil Board, 6 Persiaran Institusi, Bandar Baru Bangi, 43000 Kajang, Selangor, Malaysia.

E-mail: meihan@mpob.gov.my

\# Department of Chemistry, Faculty of Science, Universiti Malaya, 50603 Kuala Lumpur, Malaysia.
}

et al., 2004). Palm oil, wheat germ oil and rice bran oil are rich sources of tocotrienols (Aggarwal et al., 2010).

Studies have been widely carried out and reported that tocols (tocopherols and tocotrienols) are capable to protect and reduce cellular ageing and damage induced by oxidative stress (Matough et al., 2014; Nishio et al., 2013; Makpol et al., 2010). Some studies reported that tocotrienols exert more potent anti-cancer activity compared to tocopherols (Pierpaoli et al., 2010; Hiura et al., 2009; Takahashi and Loo, 2004). However, low absorption due to its poor water solubility and shorter half-life of tocotrienols compared to tocopherols has greatly hindered their therapeutic action especially when administered orally (Compadre et al., 2014; Yap et al., 2003). 
Studies have shown that reduction in the emulsion droplet size greatly improved tocotrienols solubility. Coupled with a larger surface area for interaction, this resulted in increases in mucosal permeability (Abuasal et al., 2012; Kuo et al., 2008). This resulted in our investigation of producing nanoemulsion as a potential approach to improve tocols solubility. The developed nanoemulsion will be used to produce microparticle for oral administration as it is considered as the most desirable route due to its convenience (Desai et al., 2012). Nanoemulsion also serves as an effective oxygen barrier that enhances the viability of the compound in the acidic medium of the digestive system of the stomach (De Vos et al., 2012). Apart from nanoemulsion, nanostructured lipid carriers (NLC) was also developed for cosmeceutical delivery of palm phytonutrients (Loo et al., 2014).

Sonication was one of the high energy emulsification methods that is commonly used to produce nanoemulsion. Although some researchers believed that emulsification efficiency of microfluidiser processor was superior compared to sonication, sonication emulsification remains favourable due to ease of cleaning and maintenance and is more economical whereby lower processing cost is required for scale-up production (Tang et al., 2013). Furthermore, this technique has a more flexible control over the emulsion droplet size production and narrow droplet size distribution. Sonication relies upon cavitation-induced stress to break droplets into smaller size. Cavitation is a phenomenon referring to the formation, growth and implosive collapse of acoustic bubbles in liquid medium generating liquid microjets and powerful shock wave that breaks the oil phase into water in the form of droplets. These droplets were further reduced to nano-size by violently imploding bubbles produced from localised intense turbulence and shear forces (Sivakumar et al., 2014). Parthasarathy et al. (2014) demonstrated the preparation of palm oil-based oil-in-water nanoemulsion using another type of ultrasound device known as liquid whistle hydrodynamic cavitation reactor (LWHCR).

The objective of this study was to produce tocols nanoemulsion with small average droplet size $(<100 \mathrm{~nm})$ and narrow droplet size distribution with a low polydispersity index (PDI) value using sonication. The effect of sonication amplitude (\%), duration (min), type of emulsifier combination and concentration were also investigated.

\section{MATERIALS AND METHODS}

\section{Materials}

Palm oil containing 50\% w/w tocols known as Super T50 was purchased from Supervitamins
Sdn Bhd, Johor, Malaysia. Sodium alginate, polyoxyethylene sorbitan monolaurate (Tween 20), polyoxyethylene sorbitan monooleate (Tween 80) were purchased from R \& M Marketing, Essex, United Kingdom. Polyoxyethylene lauryl ether (Brij 35) was purchased from Merck. Arabic gum and sodium azide was purchased from Sigma Aldrich. Distilled water was used for the preparation of the emulsion.

\section{Emulsion Preparation}

Sodium alginate and Arabic gum was dissolved separately in distilled water. Sodium alginate $(1 \%$ $\mathrm{w} / \mathrm{v}$ ) was dissolved in distilled water at $70^{\circ} \mathrm{C}$. The dissolved sodium alginate solution was cooled to room temperature $\left(25^{\circ} \mathrm{C}\right)$. Arabic gum $(10 \% \mathrm{w} / \mathrm{v})$ was dissolved in distilled water at room temperature $\left(25^{\circ} \mathrm{C}\right)$ and continuously stirred overnight to ensure complete dissolution. Sodium alginate solution 100 $\mathrm{ml}(1 \% \mathrm{w} / \mathrm{v})$ was added into $100 \mathrm{ml}$ Arabic gum solution $(10 \% \mathrm{w} / \mathrm{v})$ to obtain a final volume of 200 $\mathrm{ml}$ with final concentration of sodium alginate and Arabic gum $0.5 \% \mathrm{w} / \mathrm{v}$ and $5 \% \mathrm{w} / \mathrm{v}$ respectively. Sodium azide $0.02 \% \mathrm{w} / \mathrm{v}$ was added into sodium alginate/Arabic gum solution to prevent microbial growth. An emulsifier to oil ratio 1:1 was used throughout the study to determine the effect of ultrasonication parameters on droplet size and size distribution. The concentration of Tween 20 and Super T50 used was $1.5 \% \mathrm{w} / \mathrm{v}$ respectively. A total of $3 \mathrm{~g}$ Tween 20 was weighed and mixed with sodium alginate/Arabic gum solution using a magnetic stirrer on stirrer plate for $15 \mathrm{~min}$ until the emulsifier was fully dissolved. The mixture was later added into a $250 \mathrm{ml}$ beaker containing $3 \mathrm{~g}$ Super T50 and was pre-emulsified by IKA T25 digital ultra turrax attached to a S25KV-25G dispersing element for $4 \mathrm{~min}$ at $8000 \mathrm{rpm}$ to form coarse emulsion before treated with sonication. The mixing was carried out at room temperature.

\section{Ultrasonication}

A UP100 Hielscher Ultrasonic Processor (Hielscher Ultrasound Technology, Teltow, Germany), with $100 \mathrm{~W}$ output power and a frequency of $30 \mathrm{kHz}$ equipped with a $10 \mathrm{~mm}$ sonotrode, was used to perform the study. During sonication, the sonotrode was immersed into the coarse emulsion. Sonication was conducted at varying sonication time (20, 40, 60, 80 and $100 \mathrm{~min})$ and at different magnitudes of sonication amplitude $(60 \%, 80 \%$ and $100 \%$ ). The nanoemulsion was analysed after sonication without storage. During sonication, some of the energy dissipated as heat. In order to avoid rapid temperature increase in the sample, sonication was paused for $1 \mathrm{~min}$ after the sample was sonicated for $4 \mathrm{~min}$. The glassware was covered with 
aluminium foil throughout the sonication process to minimise tocols oxidation and was placed in water bath with water maintained at $25^{\circ} \mathrm{C}$ for cooling purpose. Samples were prepared in triplicate.

\section{Nanoemulsion Size Analysis and PDI}

Oil droplet size and broadness of size distribution were measured using dynamic light scattering method by Zetasizer Nano ZS (Malven Instruments, UK). The size reported corresponded to intensity weighted average hydrodynamic diameter or Z-Average diameter obtained through cumulant analysis. PDI is a dimensionless measure of the width of size distribution calculated from the cumulant analysis and ranging from 0 to 1.0. Small PDI value $(<0.08)$ indicates a nearly monodispersed population, while a large PDI $(>0.7)$ indicates a very broad distribution of droplet size. The Z-average diameter was reported as mean droplet diameter obtained from average of three measurements from three freshly prepared emulsions.

\section{Types of Emulsifiers' Combination and Concentra- tion}

The nanoemulsion formed at sonication conditions that was deemed optimal was further investigated using different type of emulsifiers' combination and concentration. Combination of emulsifiers namely (Tween 20: Tween 80), (Tween 20:Brij 35) and (Tween 80:Brij 35) were used with both having the same composition in the emulsion system. Surfactant to oil ratio was maintained at 1 throughout the study. Hydrophilic-lipophilic balance (HLB) value for Tween 20, Tween 80 and Brij 35 was 16.7, 15 and 16.9 respectively. The HLB value after combination of two emulsifiers was calculated based on Equation (1).

$\mathrm{HLB}=\mathrm{x}_{1} \mathrm{~A}_{1}+\left(1-\mathrm{x}_{1}\right) \mathrm{A}_{2}$

where,

$\mathrm{x}_{1}$ is the proportion of first emulsifier having an HLB value of $A_{1}$ and the other represents the remaining proportion of second emulsifier having an HLB value of $A_{2}$.

The effect of emulsifier concentrations on average droplet size and PDI was investigated by increasing the concentration from $0.75 \%$ to $3 \% \mathrm{w} / \mathrm{v}$ with the amount of oil used fixed throughout study.

\section{Field Emission Scanning Electron Microscopy (FE- SEM)}

Field emission scanning electron microscope (FEG Quanta 450 EDX-OXFORD) was used to investigate the morphology of nanoemulsion prepared by ultrasound. The preparation method was based on
Tang et al. (2013) with slight modification. Emulsion was diluted with distilled water and was stained with $2 \% \mathrm{w} / \mathrm{v}$ osmium oxide for an hour. Then the sample was placed on 200-mesh formwar-coated copper grid (Agar Scientific Ltd, Essex, UK) and left for $10 \mathrm{~min}$. The excess solution was drawn-off using Whatman filter paper and was left to dry at room temperature $\left(25^{\circ} \mathrm{C}\right)$. The sample was then viewed using scanning transmission electron microscopy (STEM) mode operated at high vacuum condition and at an acceleration voltage of $20 \mathrm{kV}$.

\section{Statistical Analysis}

The statistical analysis of the data was performed using a stat package in R Statistical Software (Foundation for Statistical Computing, Vienna, Austria). It is an open source for statistical computing that is distributed under the Free Software Foundation's GNU General Public License in source code form. All values obtained were reported as mean values \pm standard deviation. Significant differences in the measured mean droplet diameter and PDI of the nanoemulsions produced using various type of emulsifier and concentration was analysed by oneway analysis of variance (ANOVA) and followed by Tukey's HSD post-hoc test. The significant level for all tests $(\alpha)$ was assessed at 0.05 .

\section{RESULTS AND DISCUSSION}

\section{Effect of Amplitude and Duration of Sonication on Particle Size and PDI}

Coarse emulsion prepared from ultra turrax was too polydisperse for cumulant analysis using Zetasizer to obtain a reliable droplet size. In general, results obtained from Zetasizer showed that droplet size of the coarse emulsion was larger than $1 \mu \mathrm{m}$. When sonication amplitude increased from $60 \%$ $100 \%$, there is a reduction of droplet size from 136.1 $\pm 2.5 \mathrm{~nm}$ to $108.6 \pm 0.4 \mathrm{~nm}$ due to cavitation (Figure 1). The intensity of cavitation activity in emulsifying tocols is proportional to sonication amplitude (Leong et al., 2009). Emulsions sonicated at three different amplitudes showed that mean droplet diameter decreases with sonication time. This was observed to have two distinct phases: an initial size reduction phase followed by an equilibrium/leveling-off phase (Salvia-Trujillo et al., 2013). Sonication at amplitude of $100 \%$ from $80 \mathrm{~min}$ to $100 \mathrm{~min}$ increases the average droplet size from $104.1 \pm 2.9 \mathrm{~nm}$ to 118.1 $\pm 10.8 \mathrm{~nm}$. This was due to heat dissipated and local turbulence during sonication that has degraded the emulsifying properties of Tween 20 (Tang et al., 2012). In the present study, although the water bath temperature was maintained at $25^{\circ} \mathrm{C}$, temperature of resulting nanoemulsion after sonication every 


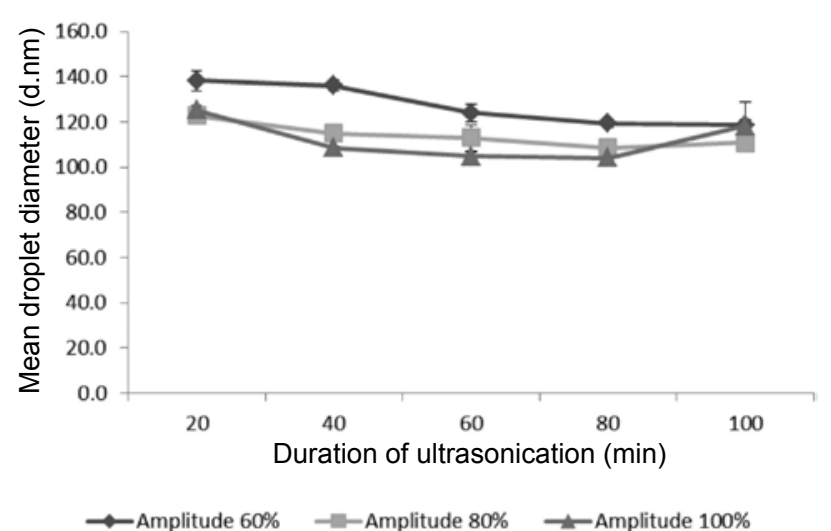

Figure 1. Effect of ultrasonication amplitude and time interval on droplet size.

20 min using $100 \%$ sonication amplitude increased from $25^{\circ} \mathrm{C}$ to $38^{\circ} \mathrm{C}-44^{\circ} \mathrm{C}$. Another explanation was that the intensified sonication forces would drove the oil droplets to the anodes and antinodes of the acoustic field and tend to collide with each other forming larger droplets as they approached closer to each other (Juliano et al., 2013). A comparison of the nano-emulsion droplet sizes produce at $60 \%, 80 \%$, $100 \%$ amplitude was observed in STEM (Figure 2), the best droplet size was illustrated in Figure $2 a$.

Increased in sonication amplitude from $60 \%$ to $100 \%$ resulted in the decrease of PDI from $0.369 \pm$ 0.011 to $0.268 \pm 0.015$ (Figure 3) except sonication amplitude of $100 \%$ from $80 \mathrm{~min}$ to $100 \mathrm{~min}$. This was due to local turbulence that generated heat that degrades the emulsifying properties of Tween 20 . Hence, sonication of $100 \%$ amplitude for 80 min was deemed as optimum condition in the present study as it produced the smallest average droplet size $104.1 \pm 2.9 \mathrm{~nm}$ and PDI value $0.215 \pm 0.008$.

\section{Effect of Different Emulsifiers Combination on the Particle Size and PDI of Tocols Nanoemulsion}

Non-ionic emulsifier was commonly used as stabiliser in tocopherol-tocotrienol emulsion (Noor Izah Zahari et al., 2014; Saberi et al., 2013; Cheong et al., 2008; Kuo et al., 2008). Non-ionic emulsifier such as Tween and Span are generally recognised as safe. They show low toxicity and irritancy on oral, parenteral and dermal administration as compared to ionic emulsifier (Pujara, 2012; Dehghan Noudeh et al., 2009). Hence, they are considered as favourable stabiliser in emulsion formulation for food, pharmaceutical and cosmeceutical industry. Each surfactant and oil has a specific HLB value. The optimum HLB obtained from selected surfactant or blend of surfactants that match the HLB of the selected oil provides a synergistic effect in enhancing the stability of emulsion by achieving the lowest interface tension between the oil and water phases (Shahin et al., 2011). The presence of surfactant a)

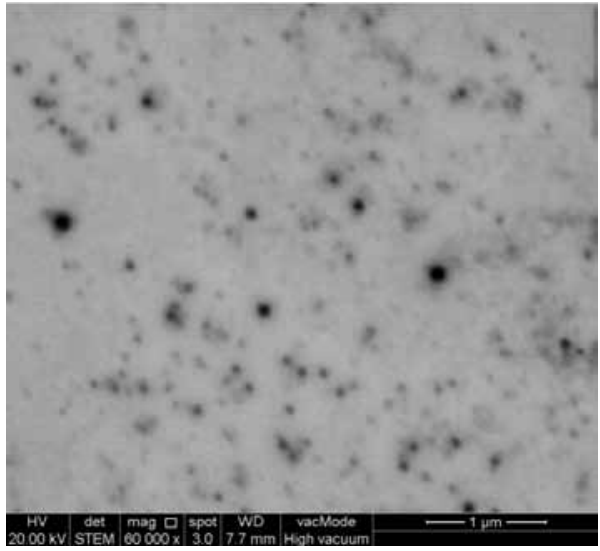

b)

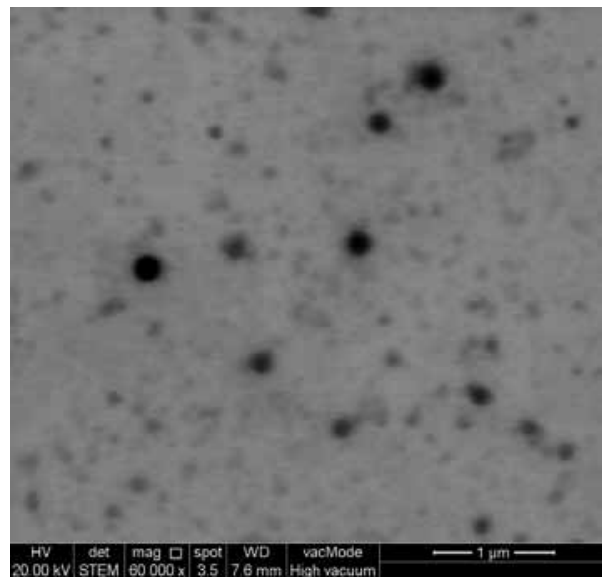

c)

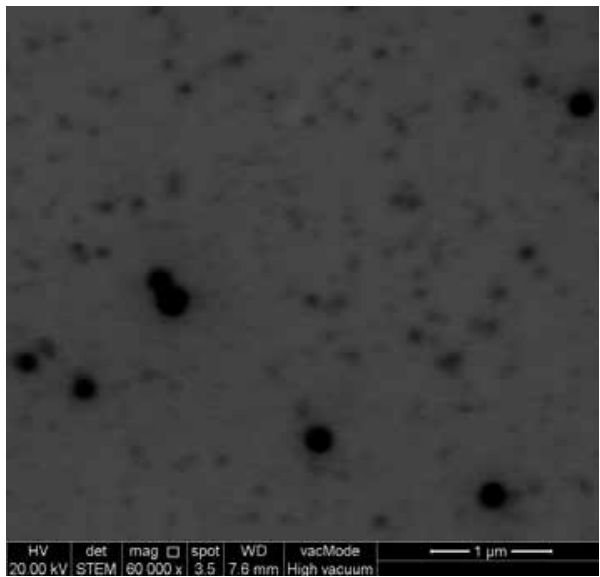

Figure 2. Scanning transmission electron microscopy (STEM) photographs of palm-based tocopherol-tocotrienol nanoemulsion prepared by (a) ultrasound (100\% amplitude), (b) ultrasound $(80 \%$ amplitude) and (c) ultrasound (60\% amplitude).

reduced interfacial tension which is proportional to the force required to deform and disrupt droplets during homogenisation (Yang and McClements, 2013; Schubert and Engel, 2004).

The combinations used in the study were (Tween 20:Tween 80), (Tween 20:Brij 35), and (Tween 80:Brij 35) with the same composition $(50: 50 \mathrm{w} / \mathrm{w})$ in the emulsion. Data obtained showed that different type of emulsifier combination has a significant effect on particle size $(\mathrm{p}<0.05)$ and PDI $(\mathrm{p}<0.05)$. As illustrated in Figure 4, (Tween 20:Brij 35) produced the smallest droplet size with an average of $52.0 \pm$ 


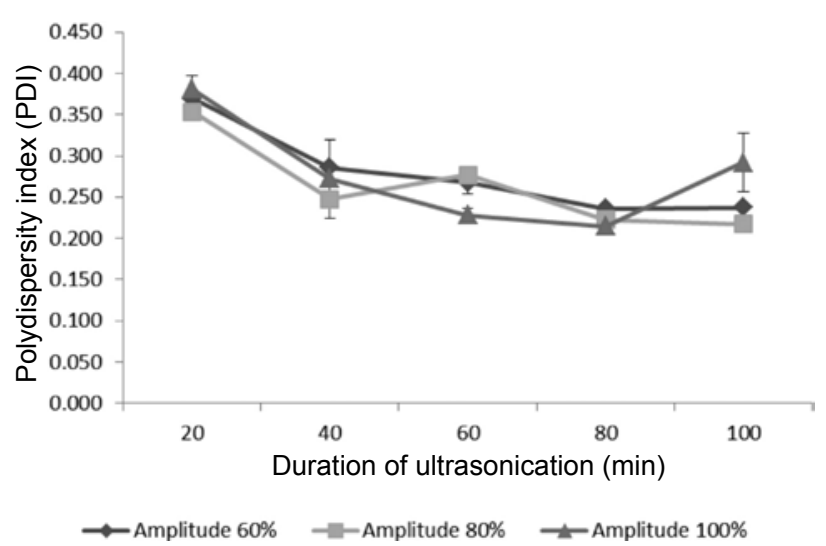

Figure 3. Effect of ultrasonication amplitude and time interval on polydispersity index (PDI).

$1.0 \mathrm{~nm}$ followed by (Tween 80:Brij 35) and (Tween 20:Tween 80) with an average droplet size of 54.8 $\pm 1.2 \mathrm{~nm}$ and $130.3 \pm 1.3 \mathrm{~nm}$ respectively. However (Tween 20:Tween 80) produced the smallest PDI $=0.225 \pm 0.005$, followed by (Tween 80:Brij 35) with PDI $=0.266 \pm 0.006$ and (Tween 20:Brij 35) with PDI $=0.301 \pm 0.004$. The results show that addition of Brij 35 has significantly reduced the droplet size $<100 \mathrm{~nm}$ as compared to the mean droplet diameter obtained from our earlier study, $104.1 \pm 2.9 \mathrm{~nm}$, by using Tween 20 alone as emulsifier. The results obtained was in agreement with Laouini et al. (2012) where it was reported that the used of combination (Tween 80: Brij 35) showed advantages over single emulsifier (either Tween 80 or Brij 35) to produce vitamin E loaded nanoemulsion that had small particle size and improved physical stability. Laouini et al. (2012) used emulsifier mixture, Tween 80-Brij 35 (50:50 $\mathrm{w} / \mathrm{w}$ ) to prepare vitamin $\mathrm{E}$ loaded nanoemulsion and droplet average size obtained was $106 \mathrm{~nm}$. Average droplet size obtained in present study was half the size smaller $(54.8 \pm 1.2 \mathrm{~nm})$. It was also comparable with the results reported by Kuo et al. (2008), where average droplet size of nanoemulsion loaded with different tocopherol isomer $(\alpha-, \gamma-$ and $\delta$-tocopherol) produced by microfluidics was $56.6 \pm$ $0.2,42.3 \pm 0.2$ and $51.5 \pm 0.5$ respectively and PDI obtained was $0.287 \pm 0.001,0.275 \pm 0.003$ and 0.272 \pm 0.005 .

The average droplet size of nanoemulsion stabilised by (Tween 20:Tween 80) is much larger than average droplet size of nanoemulsion stabilised by Tween 20 alone. During homogenisation, droplet disruption and droplet coalescence occurred simultaneously. Hence, how fast the emulsifier adsorb and completely covers the newly form oil-water interface plays an important role in preventing the oil droplets from re-coalescence. Brij 35 has smaller molecular weight compared to Tween 80 or Tween 20 thus can be quickly adsorbed onto the newly formed oil-water interface during homogenisation to prevent coalescence of droplets. As the droplet size in the emulsion system decreases to less than $100 \mathrm{~nm}$ in diameter, it appears visibly from white to transparent or translucent due to the light being weakly scattered by these fine oil droplets (Fryd and Mason, 2012). As shown in Figure 5, the

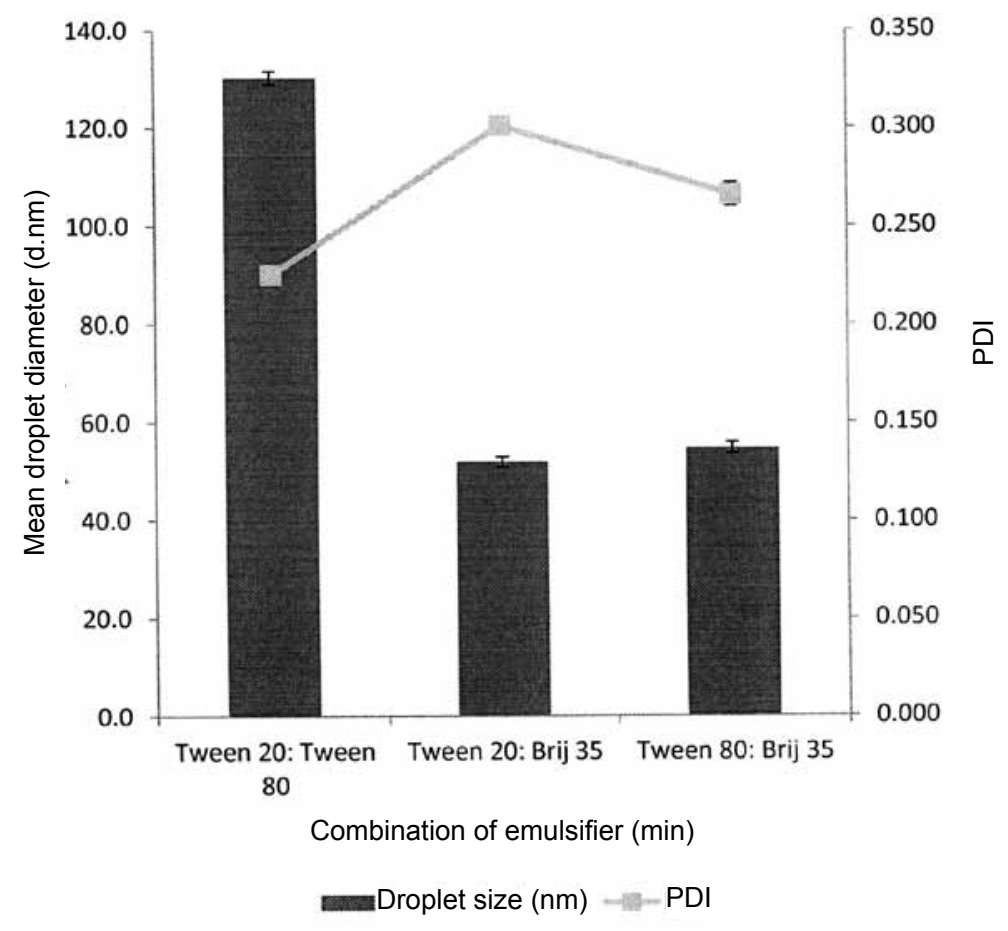

Figure 4. Influence of different type of emulsifier combination: [Tween 20:Tween 80], [Tween 20:Brij 35] and [Tween 80:Brij 35] on average droplet size and polydispersity index (PDI) of tocols nanoemulsions. 


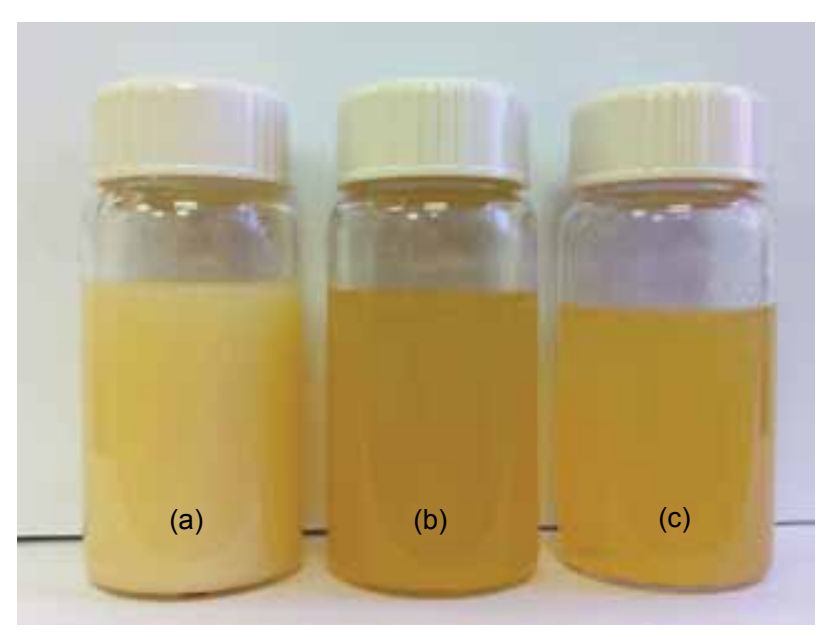

Figure 5. Palm-based tocopherol-tocotrienol nanoemulsion prepared by (a) (Tween 20: Tween 80) visually appears as white whereas (b) (Tween 20: Brij 35) and (c) (Tween 80: Brij 35) visually appears as translucent.

emulsion stabilised by (Tween 20:Tween 80) had white appearance whereas for (Tween 20:Brij 35) and (Tween 80:Brij 35) the emulsion produced appeared as translucent. Particle size and size distribution of these droplets are critical criteria that affect the stability of emulsion. In general, the smaller the average droplet size and size distribution, the emulsion formed is more stable. Combination of Tween 80 and Brij 35 was deemed for further study as the nanoemulsion produced has an average droplet size $(<100 \mathrm{~nm})$ and PDI less than 0.3.

\section{Effect of Emulsifiers Concentration on Particle Size and PDI}

Emulsifier concentration is another important variable in nanoemulsion preparation due to increase in oil-water interface area which requires more emulsifiers to completely cover the interface (Jafari et al., 2007) in preventing droplet recoalescence through steric or electrostatic repulsion. In this study, a combination of two emulsifiers Tween 80 and Brij 35 with both having the same amount of composition (50:50 w/w) were used to stabilised the emulsion. Increasing the concentration of emulsifier from $0.75 \%$ to $3 \% \mathrm{w} / \mathrm{v}$ resulted in a significant reduction $(\mathrm{p}<0.05)$ in average droplet size but significant increase in PDI $(\mathrm{p}>0.05)$ (Figure 6 ). The results revealed that although increase in concentration resulted in reduced average droplet size, however it also causes heterogeneity in the overall particle size thus leading to increase of PDI.

Figure 7 showed that as the concentration of (Tween 80: Brij 35) increases, the peaks shifted to the left indicating that the average droplet size is decreasing but the base of the peak became broader indicating a broad size distribution. When the concentration increased to $3 \% \mathrm{w} / \mathrm{v}$, a peak with droplets size of $7.7 \mathrm{~nm}$ was observed in size distribution by intensity indicating micelle formation from Tween 80 and Brij 35. Similar results was also reported by Laouini et al. (2012), when the concentration of emulsifier increases a small peak corresponding to micelle was observed in size distribution by intensity. Oh et al. (2011) and Tadros et al. (2004) reported that average droplet size will become smaller and size distribution become narrower with the increase of emulsifier concentration and eventually reached a plateau level. Beyond plateau level, free or nonadsorbed emulsifier might aggregate within itself to form micelle. Nanoemulsion is known to be thermodynamically unstable thus it tends to minimise the interfacial area through coalescence and Ostwald

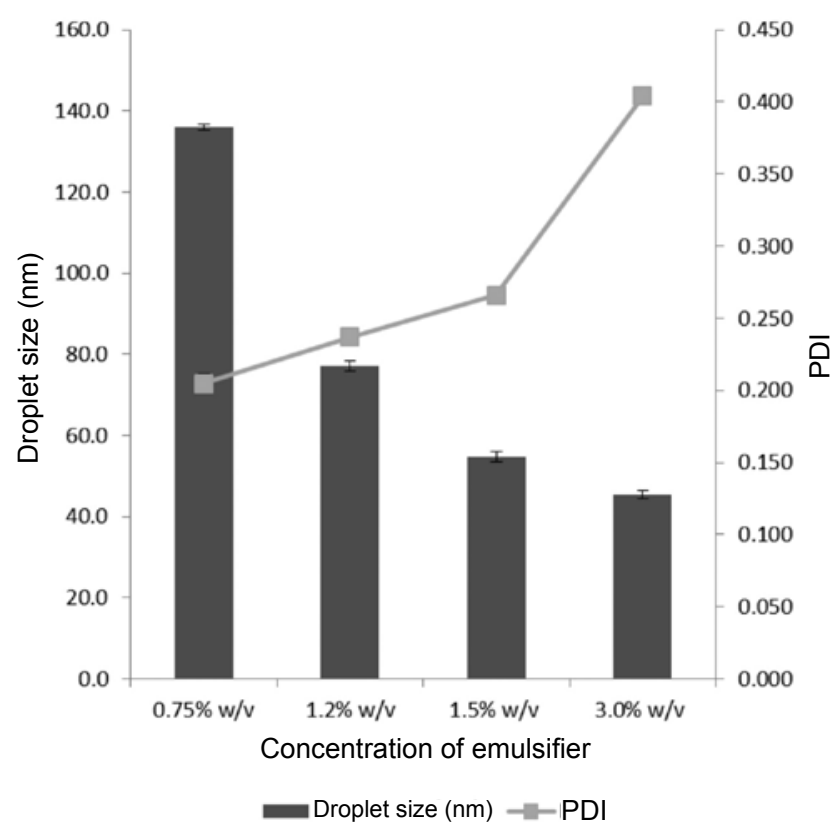

Figure 6. Influence of emulsifier concentrations on droplet size and polydispersity index (PDI) of tocopherol-tocotrienol nanoemulsion. 
Size distribution by intensity

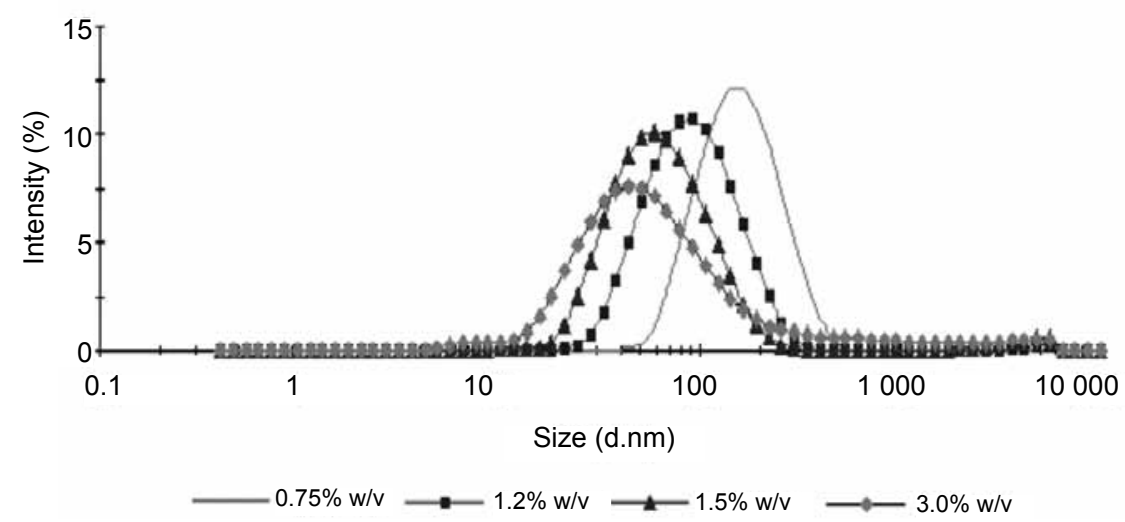

Figure 7. Size distribution by intensity obtained from different concentration of emulsion (Tween 80: Brij 35).

ripening (Nguyen Hoang et al., 2004). Formation of micelle will promote oil solubilisation and enhance the rates of Ostwald ripening. Ostwald ripening causes molecular diffusion of oil from smaller droplets to larger droplets due to greater solubility of smaller droplets in continuous phase. Thus, smaller droplets will shrink while larger droplets continue to grow and destabilise emulsion (De Smet et al., 1999).

It was noted that as the emulsifier concentration increases, the percentage of minor peak representing larger droplet size increased. One possible explanation was the competition between (Tween 80: Brij35) and Arabic gum in stabilising the emulsion. Besides widely used as wall material for encapsulation purposes, Arabic gum is also used as emulsifier as it exhibits emulsifying activity due to the presence of arabinogalactan protein (AGP) fraction (Ma et al., 2015; Fernandes et al., 2014). As concentration of Tween 80 and Brij 35 increases, free or nonadsorbed Arabic gum induces particle coalescence via bridging flocculation, depletion flocculation, and other mechanisms (Anarjan et al., 2013; Jafari et al., 2007). Based on the finding, the suitable concentration of emulsifier used was deemed as $1.5 \% \mathrm{w} / \mathrm{v}$ since increasing the concentration of emulsifier by two-fold led to formation of micelle but lowering the concentration $(<1.5 \% \mathrm{w} / \mathrm{v})$ led to increase in average droplet size. Furthermore, in order to minimise the PDI and potential cytotoxicity effect exhibits by non-ionic emulsifier, it is desirable to minimise the concentration of emulsifier used during preparation so that the formulation was applicable for oral administration (Ali et al., 2010).

\section{Stability of Nanoemulsion of Tocopherol-tocotrie- nol}

The stability of emulsion can be determined by monitoring the diameter of dispersed oil droplets and their size distribution over time. In the present study, the stability of tocols nanoemulsion was prepared by a combination of Tween 80:Brij 35 at $50: 50 \mathrm{w} / \mathrm{w}$ at a concentration of $1.5 \% \mathrm{w} / \mathrm{v}$ and stored at $4^{\circ} \mathrm{C}$. As shown in Figures $8 a$ and $8 b$, slight increase in droplet size and PDI was observed on second day. However, droplet size and PDI remained fairly stable on the following days. This can be attributed to the presence of emulsifier that adsorbed onto the oil droplets surface formed a protective layer

a)
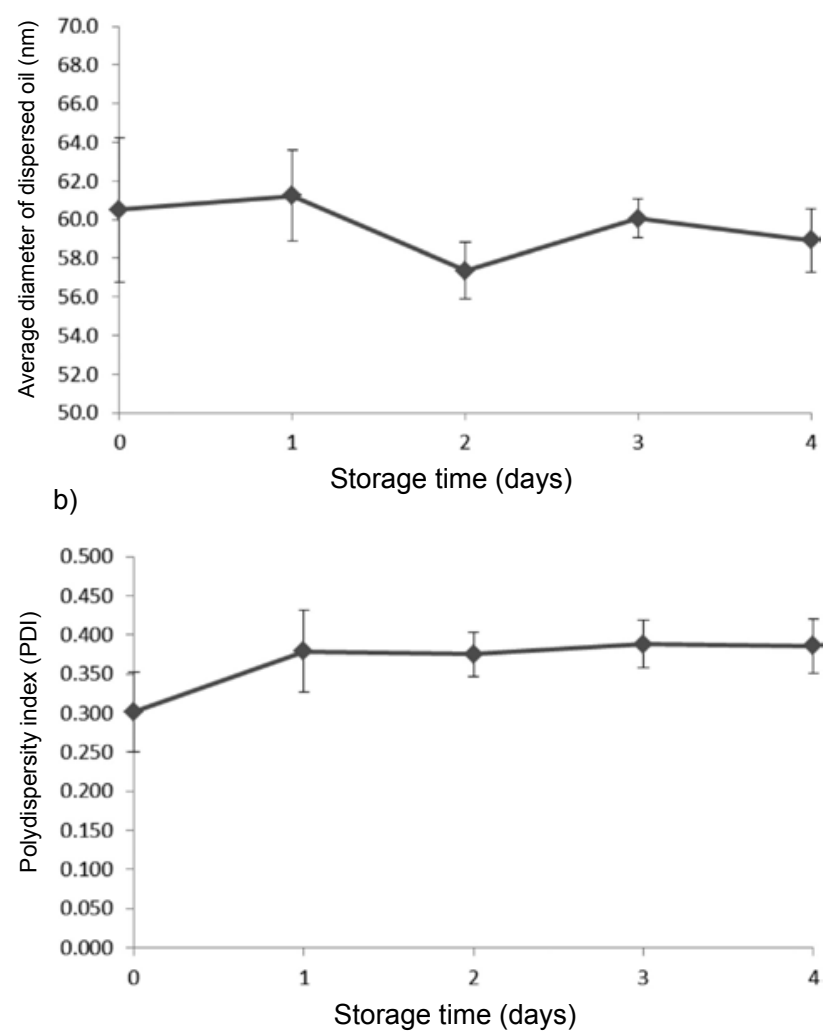

Figure 8. Stability of tocopherol-tocotrienol nanoemulsion prepared during storage duration at $4^{\circ} \mathrm{C} ;$ a) changes in average diameter of dispersed oil droplets and $b$ ) changes in polydispersity index (PDI). 
that helped to hinder the droplets from being recoalescence through steric repulsive force (Hebishy et al., 2013). Furthermore, it was postulated that storage at low temperature is able to slow down the mobilities of the oil droplets and thus, reduce the tendency of flocculation and coalescence (Masoud et al., 2012).

In general, long-term stability study would be appropriate to support the real stability of the developed nanoemulsions. For controlled release application, the nanoemulsion produced will not be kept for long period of time. Cainero et al. (2013) reported that microparticles formed from emulsion that showed poor stability exhibit low encapsulation efficiency. As such, any nanoemulsion that is tested to be unstable within four days of production is deemed unfit for encapsulation application.

\section{CONCLUSION}

The formulation of $1.5 \% \mathrm{w} / \mathrm{v}$ emulsifier blend (Tween 80:Brij $35=50: 50 \mathrm{w} / \mathrm{w}), 1.5 \% \mathrm{w} / \mathrm{v}$ palm-based tocols, $5 \% \mathrm{w} / \mathrm{v}$ Arabic gum and $0.5 \% \mathrm{w} / \mathrm{v}$ sodium alginate produced tocols nanoemulsion of average droplet size of $60 \mathrm{~nm}$ by sonication at power amplitude of $100 \%$ for $80 \mathrm{~min}$. Good physical stability of tocols nanoemulsion is an important factor to ensure production of calcium alginate bead encapsulated with high tocols content. In vitro release study of calcium alginate bead will be carried out in future study to evaluate percentage cumulative release of tocols from the beads under a period of time. The calcium alginate beads formed were intended to overcome short elimination half-life of tocotrienols by prolonging the duration of tocotrienols retained within body by controlled release of tocols from the beads. Parameter such as polysaccharide concentration on encapsulation efficiency and cumulative release is also recommended to be incorporated in future study.

\section{ACKNOWLEDGEMENT}

The authors would like to thank the DirectorGeneral of MPOB for the financial support of this study, the Engineering and Processing Research Division for providing the equipment and facilities. The authors also wish to thank the IPPP Research Laboratory, Universiti Malaya for their assistance, and providing the equipment and facilities.

\section{REFERENCES}

ABUASAL, B S; QOSA, H; SYLVESTER, P W and KADDOUMI, A (2012). Comparison of the intestinal absorption and bioavailability of $\gamma$-tocotrienol and $\alpha$-tocopherol: in vitro, in situ and in vivo studies. Biopharmaceutics \& Drug Disposition, 33: 246-256.

ALI, H; SHIRODE, A B; SYLVESTER, P W and NAZZAL, S (2010). Preparation and in vitro antiproliferative effect of tocotrienol loaded lipid nanoparticles. Colloids and Surfaces A: Physicochemical and Engineering Aspects, 353: 43-51.

ANARJAN, N; NEHDI, I A and TAN, C P (2013). Influence of astaxanthin, emulsifier and organic phase concentration on physicochemical properties of astaxanthin nanodispersions. Chemistry Central J., 7: 127-138.

AGGARWAL, B B; SUNDARAM, C; PRASAD, S and KANNAPPAN, R (2010). Tocotrienols, the vitamin E of the $21^{\text {st }}$ century: its potential against cancer and other chronic diseases. Biochemical Pharmacology, 80: 1613-31.

CARNEIRO, H C F; TONON, R V; GROSSO, C R F and HUBINGER, M D (2013). Encapsulation efficiency and oxidative stability of flaxseed oil microencapsulated by spray drying using different combinations of wall materials. J. Food Engineering, 115: 443-451.

CHEONG, J N; TAN, C P; MAN, Y B C and MISRAN, M (2008). $\alpha$-Tocopherol nanodispersions: preparation, characterization and stability evaluation. J. Food Engineering, 89: 204-209.

COMPADRE, C M; SINGH, A; THAKKAR, S; ZHENG, G; BREEN, P J; GHOSH, S; KIAEI, M; BOERMA, M; VARUGHESE, K I and HAUERJENSEN, M (2014). Molecular dynamics guided design of tocoflexol: a new radioprotectant tocotrienol with enhanced bioavailability. Drug Development Research, 75: 10-22.

DEHGHAN NOUDEH, G; KHAZAELI, P; MIRZAEI, $S$; SHARIFIFAR, F and NASROLLAHOSAIANI, $S$ (2009). Determination of the toxicity effect of sorbitan esters surfactants group on biological membrane. J. Biological Sciences, 9: 423-430.

DESAI, P P; DATE, A A and PATRAVALE, V B (2012). Overcoming poor oral bioavailability using nanoparticle formulations - opportunities and limitations. Drug Discovery Today: Technologies, 9: 8795.

DE SMET, Y; DERIEMAEKER, L and FINSY, R (1999). Ostwald ripening of alkane emulsions in the presence of surfactant micelles. Langmuir, 15: 67456754 . 
DE VOS, P; FAAS, $\mathrm{M}$ M; SPASOJEVIC, $\mathrm{M}$ and SIKKEMA, J (2010). Encapsulation for preservation of functionality and targeted delivery of bioactive food components. International Dairy J., 20: 292-302.

FERNANDES, R V; BORGES, S V and BOTREL, D A (2014). Gum arabic/starch/maltodextrin/inulin as wall materials on the microencapsulation of rosemary essential oil. Carbohydrate Polymers, 101: 524-532.

FRYD, M M and MASON, T G (2012). Advanced nanoemulsions. Annual Review of Physical Chemistry, 63: 493-518.

GEE, P T (2011). Vitamin E - essential knowledge for supplementation. Lipid Technology, 23: 79-82

HEBISHY, E; BUFFA, M; GUAMIS, B and TRUJILLO, A J (2013). Stability of sub-micron oil-inwater emulsions produced by ultra high pressure homogenization and sodium caseinate as emulsifier. Chemical Engineering Transactions, 32: 1813-1818.

HIURA, Y; TACHIBANA, H; ARAKAWA, R; AOYAMA N; OKABE, M; SAKAI, M and YAMADA, $\mathrm{K}$ (2009). Specific accumulation of gamma- and deltatocotrienols in tumor and their antitumor effect in vivo. The J. Nutritional Biochemistry, 20: 607-613.

JAFARI, S M; HE, Y and BHANDARI, B (2007). Production of sub-micron emulsions by ultrasound and microfluidization techniques. J. Food Engineering, 82: $478-488$.

JULIANO, P P; SWIERGON, R; MAWSON, K; KNOERZER and AUGUSTIN, M A (2013). Application of ultrasound for oil separation and recovery of palm oil. J. Amer. Oil Chem. Soc., 90: 579588 .

KUO, F; SUBRAMANIAN, B; KOTYLA, T; WILSON, $\mathrm{T} A$; YOGANATHAN, $\mathrm{S}$ and NICOLOSI, R J (2008). Nanoemulsions of an anti-oxidant synergy formulation containing gamma tocopherol have enhanced bioavailability and anti-inflammatory properties. International J. Pharmaceutics, 363: 206213.

LAOUINI, A; FESSI, H and CHARCOSSET, C (2012). Membrane emulsification: a promising alternative for vitamin E encapsulation within nanoemulsion. J. Membrane Science, 423-424: 85-96.

LEONG, T S H; WOOSTER, T J; KENTISH, S E and ASHOKKUMAR, M (2009). Minimising oil droplet size using ultrasonic emulsification. Ultrasonics Sonochemistry, 16: 721-727.
LOO, C H; ISMAIL, R; BASRI, M; LAU, H L N; TEJO, B A; ABU HASSAN, H; CHOO, Y M and KANTHIMATHI, M S (2014). Nanostructured lipid carriers (NLC) for efficient delivery of palm phytonutrients. J. Oil Palm Res. Vol. 26: 232-239.

MA, F; BELL, A E; DAVIS, F J and CHAI, Y (2015). Effects of high hydrostatic pressure and chemical reduction on the emulsification properties of gum Arabic. Food Chemistry, 173: 569-576.

MAKPOL, S; ABIDIN, A Z; SAIRIN, K; MAZLAN, M; TOP, G M and NGAH, W Z W (2010). $\gamma$-Tocotrienol prevents oxidative stress-induced telomere shortening in human fibroblasts derived from different aged individuals. Oxidative Medicine and Cellular Longevity, 3: 35-43.

MASOUD, M E A; SARINGAT, H B and OSAMA, M A (2012). The influence of sucrose ester surfactants and different storage conditions on the preparation of a novel Swietenia macrophylla oil nanoemulsion. International Research J. Pharmacy, 3: 199-207.

MATOUGH, F A; BUDIN, S B; HAMID, Z A; ABDUL-RAHMAN, $\mathrm{M}$; AL-WAHAIBI, $\mathrm{N}$ and MOHAMMED, J (2014). Tocotrienol-rich fraction from palm oil prevents oxidative damage in diabetic rats. Sultan Qaboos University Medical J., 14: 95-103.

NG, M; CHOO, Y; MA, A; CHUAH, C and HASHIM, $M$ (2004). Separation of vitamin E (tocopherol, tocotrienol, and tocomonoenol) in palm oil. Lipids, 39: 1031-1035.

NGUYEN HOANG, T K; BINH LA, V; DERIEMAEKER, L and FINSY, R (2004). Ostwald ripening and solubilization in alkane in water emulsions stabilized by different surfactants. Physical Chemistry Chemical Physics, 6: 1413-1422.

NISHIO, K; HORIE, M; AKAZAWA, Y; SHICHIRI, M; IWAHASHI, H; HAGIHARA, Y; YOSHIDA, Y and NIKI, E (2013). Attenuation of lipopolysaccharide (LPS)-induced cytotoxicity by tocopherols and tocotrienols. Redox Biology, 1: 97-103.

NOOR IZAH ZAHARI; BASRI, M; BASRI, H; MALEK, E A and KARJIBAN, R A (2014). The palm kernel oil ester nanoemulsion system using Pluronic F-127 as a polymeric surfactant via a high energy emulsification method. J. Oil Palm Res. Vol. 26: 120124.

OH, D H; BALAKRISHNAN, P; OH, Y K; KIM, D D; YONG, C S and CHOI, H G (2011). Effect of process parameters on nanoemulsion droplet size and distribution in SPG membrane emulsification. International J. Pharmaceutics, 404: 191-197. 
PARTHASARATHY, S; SIAH YING, T and MANICKAM, S (2013). Generation and optimization of palm oil-based oil-in-water $(\mathrm{O} / \mathrm{W})$ submicronemulsions and encapsulation of curcumin using a Liquid Whistle Hydrodynamic Cavitation Reactor (LWHCR). Industrial $\mathcal{E}$ Engineering Chemistry Research, 52: 11829-11837.

PIERPAOLI, E; VIOLA, V; PILOLLI, F; PIRODDI, M; GALLI, F and PROVINCIALI, M (2010). Gamma- and delta-tocotrienols exert a more potent anticancer effect than alpha-tocopheryl succinate on breast cancer cell lines irrespective of HER-2/neu expression. Life Sciences, 86: 668-675.

PUJARA, N G (2012). Self emulsifying drug delivery system: a novel approach. International J. Current Pharmaceutical Research, 2: 18-23.

R CORE TEAM (2013). R: A language and environment for statistical computing. R Foundation for Statistical Computing, Vienna, Austria. ISBN 3-900051-07-0, URL http:/ / www.R-project.org/

SABERI, A H; FANG, $\mathrm{Y}$ and MCCLEMENTS, D J (2013). Fabrication of vitamin E-enriched nanoemulsions: factors affecting particle size using spontaneous emulsification. J. Colloid and Interface Science, 391: 95-102.

SALVIA-TRUJILLO, L; ROJAS-GRAÜ, A; SOLIVAFORTUNY, R and MARTÍN-BELLOSO, O (2013). Physicochemical characterization of lemongrass essential oil - alginate nanoemulsions: effect of ultrasound processing parameters. Food and Bioprocess Technology, 6: 2439-2446.

SCHUBERT, H and ENGEL, R (2004). Product and formulation engineering of emulsions. Chemical Engineering Research and Design, 82: 1137-1143.

SHAHIN, M; HADY, S A; HAMMAD, $M$ and MORTADA, N (2011). Novel jojoba oil-based emulsion gel formulations for clotrimazole delivery. American Association of Pharmaceutical Scientists, 12: 239-247.
SIVAKUMAR, M; TANG, S Y and TAN, K W (2014). Cavitation technology - a greener processing technique for the generation of pharmaceutical nanoemulsions. Ultrasonics Sonochemistry, 21: 20692083.

TADROS, T; IZQUIERDO, P; ESQUENA, J and SOLANS, C (2004). Formation and stability of nanoemulsions. Advances in Colloid and Interface Science, 108-109: 303-318.

TAKAHASHI, K and LOO, G (2004). Disruption of mitochondria during tocotrienol-induced apoptosis in MDA-MB-231 human breast cancer cells. Biochemical Pharmacology, 67: 315-324.

TAN, C P and NAKAJIMA, M (2005). $\beta$-Carotene nanodispersions: preparation, characterization and stability evaluation. Food Chemistry, 92: 661-671.

TANG, S Y; MANICKAM, S; WEI, T K and NASHIRU, B (2012). Formulation development and optimization of a novel Cremophore ELbased nanoemulsion using ultrasound cavitation. Ultrasonics Sonochemistry, 19: 330-345.

TANG, S Y, SHRIDHARAN, P and SIVAKUMAR, $M$ (2013). Impact of process parameters in the generation of novel aspirin nanoemulsions-comparative studies between ultrasound cavitation and microfluidizer. Ultrasonics Sonochemistry, 20: 485-97.

YANG, Y and MCCLEMENTS, D J (2013). Encapsulation of vitamin $\mathrm{E}$ in edible emulsions fabricated using a natural surfactant. Food Hydrocolloids, 30: 712-720.

YAP, S P; YUEN, K H and LIM, A B (2003). Influence of route of administration on the absorption and disposition of $\alpha,-\gamma$ - and $\delta$-tocotrienols in rats. $J$. Pharmacy and Pharmacology, 55: 53-58. 